\title{
Água, saúde e territórios: uma breve discussão
}

\author{
GURGEL, Helen C. ${ }^{1}$ \\ BILLA, Michèle ${ }^{2}$ \\ MAZZEGA, Pierre ${ }^{3,4}$ \\ ${ }^{1}$ Laboratório de Geografia, Ambiente e Saúde (LAGAS), Universidade de Brasília, Brasília, Brasil. helengurgel@unb.br \\ ${ }^{2}$ Pharmacienne Diplomée d'Etat, Cergy Pontoise, France. fabien-billa@orange.fr \\ ${ }^{3}$ IJL Observatory of Environmental Changes, IRD / University of Brasilia, Brasilia, Brazil. \\ ${ }^{4}$ Geosciences Environment Toulouse, IRD / CNRS / University of Toulouse, France. pierre.mazzega@ird.fr
}

\section{Resumo}

A água e o meio ambiente, recursos vitais, interagem de várias maneiras com a saúde humana: vetor de agente microbiano ou tóxicos, ambiente de vida de vetores biológicos ou ainda importante meio de favorecimento de desenvolvimento de epidemias durante e após eventos extremos. Todas essas dimensões de interação entre a água e a saúde humana são tema de políticas públicas diferenciadas, em escalas que variam da supranacional ao local nos territórios que se apresentam hora como locais de apropriação e de vida e hora como lugar de expressão das políticas. Após uma apresentação das principais doenças de maior preocupação para a saúde pública global relacionada à água (amebíase (diarreia), esquistossomose e malária), apresentamos a situação mais específica do território brasileiro, principalmente no que diz respeito à diarreia infantil, a contaminação por cianobactérias e as doenças vetoriais: malária, dengue, esquistossomose e leptospirose, apresentamos algumas medidas recentemente implementadas pelo governo brasileiro para tentar suplantar as questões ligadas à relação entre água e a saúde.

Palavras-Chave: Água, Saúde, Territórios, Políticas Publicas, Brasil

\begin{abstract}
Water, at the same time environment and vital resource, interacts in various ways on human health: vector for microbial or toxic agents, living environment for biological vectors, or natural power fostering the development of epidemics during extreme events or disasters. All these dimensions of interaction with human health are the subject of differentiated public policies, at the supranational, national and local scales, in territories that play both as places of ownership and life but also as places for the expression of measures of policies and survey, prevention and health. After a presentation of some water-related diseases among those of greatest concern for global public health (amebiasis, schistosomiasis / bilharziosis and malaria), we present the more specific situation of the Brazilian territory, particularly with regard to infant diarrhea, malaria and dengue, the schistosomiasis and leptospirosis, and some of the measures recently implemented by the Brazilian Government to try to stop it.
\end{abstract}

Keywords: Water, Health, Territories, Public Policy, Brazil. 


\section{A Água, o Lugar e o Território}

Água é essencial para o funcionamento biológico em todos os níveis, desde o metabolismo dos organismos vivos até o equilíbrio dos ecossistemas. Na biologia humana é essencial para sua fisiologia, conforto e higiene. A escala da sociedade constitui um recurso indispensável a um grande número de atividades, sendo que algumas têm um importante papel econômico desde o desenvolvimento local até o regional.

Contudo estima-se, que cerca de 1,5 bilhões de pessoas em todo o mundo não tenham acesso a água de boa qualidade (UN Statistics Division, 2008). Cerca de 80 países sofrem de estresse hídrico ("water stress"), definido como situações nas quais há um escoamento superficial de chuva menor que $1000 \mathrm{~m}^{2} /$ pessoa/ano (Arnell, 2004). A população nestas regiões compreende cerca de $40 \%$ do total mundial.

Em 2002, 21\% da população dos países em desenvolvimento não tinham acesso continuado a fontes adequadas de água (UNSD, 2008). Diante deste contexto as Nações Unidas têm como parte de uma das Metas de Desenvolvimento do Milênio a redução em $50 \%$, até 2015 , da proporção da população mundial, em 1990, sem acesso à água de boa qualidade para beber e ao esgotamento sanitário adequado.

Deve-se resaltar que desde 1948, com a criação da Organização Mundial da Saúde, passasse a firmar que saúde é "...um estado de completo bem-estar físico, mental e social e não simplesmente a ausência de doença".

A ampliação do debate sobre o conceito de saúde e também sobre o campo da saúde passasse a reforçar a convicção de que a saúde não é um assunto só para médicos (e pacientes). Sendo que em 1986 a Carta de Ottawa produzida durante a I Conferência Internacional sobre Promoção de Saúde no Canadá declara que "A paz, a educação, a habitação, a alimentação, a renda, um ecossistema estável, a conservação dos recursos, a justiça social e a equidade são requisitos fundamentais para a saúde".

Diante deste contexto, a água tão essencial para a nossa vida é dispersa de forma heterogênea sobre o espaço geográfico e utilizada de maneira diferenciada pelos diversos atores sociais que compõe esse espaço. Assim é importante discutirmos formas de análise espaciais das questões relativas à água e a saúde.

Devemos destacar que uma das formas de olhar a relação água e saúde perpassa pelo lugar, que é a porção ou parte do espaço em que vivemos é nele onde ocorre o nosso cotidiano e que vivenciamos as nossas experiências. Há lugares simples com reduzido números de elementos (áreas rurais ou pequenas cidades) e lugares complexo com grande diversidade de elementos (grandes cidades).

Os espaços podem ser visto como conjuntos de territórios e lugares onde fatos acontecem simultaneamente, e, suas repercussões são sentidas em sua totalidade de maneiras diferentes. Cada fato é percebido com maior ou menor intensidade de acordo com a organização sócio espacial, cultural, político e econômica de cada população que habita e produz cada um desses lugares apontando assim relações heterogêneas entre água é saúde (Godim et al., 2008).

O território segundo Monken e Barcellos (2005) apresenta muito mais que uma extensão geométrica, apresenta também um perfil demográfico, epidemiológico, administrativo, tecnológico, político, social e cultural que o caracteriza e se expressa num território em permanente construção. O território é então o resultado de uma acumulação de situações históricas, ambientais, sociais que promovem condições particulares para a produção de doenças. O reconhecimento desse território é um passo básico para a caracterização da população e de seus problemas de saúde, bem como para avaliação do impacto dos serviços sobre os níveis de saúde dessa população. Esse reconhecimento é realizado através da observação das condições criadas no espaço para a produção, circulação, residência, comunicação para o exercício da política e das crenças, para o lazer e como condição de vida.

Não devemos esquecer que os territórios são construídos e desconstituídos dentro de escalas temporais diferentes (séculos, décadas, anos, dias). Além disso, o território tem a capacidade de congregar informações de múltiplas fontes e de múltiplas disciplinas.

Devemos destacar que no território é onde as coisas acontecem: onde as pessoas vivem, trabalham, se divertem, adoecem e se recuperam. Sendo que um dos pontos de maior destaque é que o território é o local de aplicação das políticas públicas é onde as decisões se tornam realidades. Esse contexto mostra a relevância de se analisar as relações entre saúde e ambiente através do território.

\section{2. Água e Saúde}

Atualmente estima-se que cerca de $10 \%$ da carga global de doenças seja devida à má qualidade da água e a deficiências na disposição de 
excretas e na higiene (Prüss-Ustin et al., 2008). A ONU estima que 3.900 crianças morram por dia de doenças relacionadas com água suja.

Quase 90\% dos cerca de 4 bilhões de episódios anuais de diarreia, em todo o mundo, (que causam 1,8 milhões de mortes em menores de cinco anos) são atribuídos a deficiências no esgotamento sanitário e na provisão de água de boa qualidade. Por outro lado, sabe-se que até $94 \%$ dos casos de diarreia são passíveis de prevenção (WHO/UNICEF, 2006).

A água aparece então como veículo de doença e de saúde. Segundo Confaloniere et al. (2010) a água relaciona-se à saúde humana de várias maneiras e as principais são:

1. Como veículo de agentes microbianos causadores de gastrenterites, especialmente por causa da contaminação fecal, ou de outras infecções como leptospirose, comum em inundações urbanas.

2. Como veículo de agentes tóxicos, quer naturais (ex. toxinas biológicas, como as das cianobactérias; arsênico) ou de origem antrópica (outros contaminantes químicos).

3. Como reservatório de vetores de doenças, como por exemplo, os mosquitos transmissores da malária e da dengue e os hospedeiros intermediários (caramujos) que albergam - parasita causador da esquistossomose (Schistosoma mansoni).

4. Impactos físicos diretos (ex. inundações em áreas povoadas) ou indiretos (ex. danos à produção de alimentos ou à infraestrutura de saúde, etc.).

Para ilustrar alguns desses relacionamentos, vamos abordar rapidamente aqui a epidemiologia e as formas de contaminação associadas a três doenças de particular importância na saúde global: amebíase (diarreia), esquistossomose e malária.

\subsection{Amebíase}

Amebíase é uma das principais doenças parasitárias e se caracteriza pela manifestação de diarreias. Em todo o mundo: cerca de 100.000 pessoas morrem a cada ano devido à amebíase do cólon ou de tecidos, 50 milhões têm evidência de amebíase intestinal e 500 milhões são portadores de ameba não patogênica (não desenvolve sintomas).

A amebíase é causada por uma ameba que vivem em água doce ou salgada, onde se alimenta principalmente de micro algas ou outros menores protozoários por fagocitose. Há duas situações distintas: uma causada por Entamoeba histolytica, responsável pela amebíase intestinal ou do tecido, por vezes, grave ou mesmo fatal; e a causada pela Entamoeba dispar, esta última é assintomática, incluindo em pacientes com AIDS. Ela é responsável pela maioria dos portadores assintomáticos, é importante para os pacientes distinguir entre a Entamoeba histolytica, que é patogênica no trato digestivo do homem e a Entamoeba dispar, morfologicamente idênticas, mas não é patogênica (Chauvelot, 2006 e Picot, 2006).

A amebíase é mais frequente em países em desenvolvimento onde as condições de saneamento são insuficientes e são afetadas pela superpopulação e a pobreza. A maioria dos doentes é contaminada pela ingestão de água ou alimentos contaminados pelos cistos da Entamoeba histolytica. Esses cistos são excretados nas fezes de doentes ou portadores saudáveis e resistem várias semanas em ambientes úmidos. Os seres humanos são o principal reservatório do parasita. México, Índia e alguns países africanos são particularmente afetados, mas a doença pode ocorrer esporadicamente ou de forma epidêmica em qualquer área onde a água potável entra em contato com dejetos humanos, como é o caso durante as inundações ou outros desastres naturais. A diabetes é um fator que contribui para as complicações da amebíase intestinal patogênica (Chauvelot, 2006 e Picot, 2006).

\subsection{Esquistossomose}

É uma doença parasitária causada por vermes chamados schistosomas, das quais existem cinco espécies que parasitam os humanos. O ciclo de vida envolve um hospedeiro intermediário, um molusco que vive em água doce, que permite a maturação das larvas de schistosomas e sua liberação para o meio ambiente aquático. O ser humano é infectado pelo simples contato com a água doce (lagos, lagoas, rios) caso o parasita, neste estágio atravesse a pele. A esquistossomose afeta cerca de 200 milhões de pessoas em mais de 70 países, com mais de 500 mil mortes por ano. Infecção com schistosomas leva a esquistossomose, que tem repercussões físicas, mas também intelectuais nos indivíduos infectados. O percentual de mortalidade é menos dramático do que para a malária ou a AIDS, mas a doença tem implicações importantes para a morbidade e, consequentemente, no desenvolvimento econômico dos países (Capron, 2004).

Atualmente se estabeleceu que a propagação da esquistossomose deve-se à proliferação de sistemas de irrigação, de açudes e de 
lagoas temporárias. Embora útil estes sistemas de irrigação eles se constituem preocupações para saúde pública, porque favorecem o crescimento de caramujos de água doce que são hospedeiros intermediários da esquistossomose. Ao tomar banho em água doce infetada as pessoas podem contrair o parasita. As consequências são, entre outras, a diminuição da produtividade de adultos e interrupções na escolaridade em crianças.

Há cinco espécies de trematódeos: Schistosoma mansoni, responsável pela esquistossomose intestinal (África, Mediterrâneo oriental, Caribe, América do Sul e sudeste de Madagascar), Schistosoma haematobium responsável pela esquistossomose urinária (África, Mediterrâneo oriental e leste e nordeste Madagascar), Schistosoma japonicus causador da esquistossomose intestinal (sudeste da Ásia e do Pacífico ocidental), Schistosoma intercalatum na África central e Schistosoma mekongi na Bacia do Mekong (Capron, 2004).

Em áreas endêmicas, as pessoas que realizam trabalhos de irrigação e as mulheres que cuidam das tarefas domiciliares, como lavar roupas, são as mais expostas a infecção por larvas de schistosomas que penetram através da pele. Elas, então, se desenvolvem na pele e nos pulmões, em seguida, elas se fixam no fígado. Esses vermes podem viver por 25 anos no estado de acoplamento permanente. $O$ resultado é uma alta fertilidade de fêmeas que põem milhões de ovos durante este tempo. Esses ovos podem ser excretados nas fezes no caso da esquistossomose intestinal, ou pela urina na esquistossomose urinária. Desde a eliminação dos ovos em água doce, o embrião já é liberado. Ele nada e encontra seu hospedeiro intermediário (o caramujo Biomphalaria glabrata), eles se desenvolvem por um fenômeno extraordinário a poliembrionia, pois de apenas um miracídio pode resultar $500 \mathrm{mil}$ cercárias infectantes (Capron, 2004).

\subsection{Malária}

Esta é uma doença parasitária infecciosa causada por uma infecção por protozoários, o qual existem quatro espécies do gênero Plasmodium. A malária é a doença infecciosa mais mortal no mundo de hoje: segundo a Organização Mundial de Saúde, a malária mata a cada ano entre 1,5 e 2,7 milhões de pessoas, incluindo um milhão de crianças menores de cinco anos. Dois bilhões de pessoas, ou seja, $40 \%$ da população mundial estão expostas. Uma centena de países do mundo é afetada, principalmente na zona tropical desfavorecida (mais de $90 \%$ dos casos ocorrem na África).
Quatro espécies de parasitas são responsáveis pela malária. Eles diferem na sua distribuição geográfica e na sua gravidade potencial (Chauvelot, 2003; Paillat, 2003): 1) Plasmodium falciparum é a responsável pela forma mais letal, é encontrada em regiões tropicais da Ásia, América Latina e regiões da África onde é a predominante; 2) Plasmodium vivax tem distribuição em todo o mundo tropical como a forma anterior, bem como em algumas zonas temperadas; 3 ) Plasmodium ovale é a forma mais rara, ocorre principalmente na África ocidental. Ela pode causar recaídas a cada 4 ou 5 anos após a primeira crise, mas não é fatal; 4) Plasmodium malariae, pode dar recaída depois de 20 anos, mas não mata, é distribuída de forma muito desigual em todo o mundo.

Os plasmódios têm um ciclo de vida complexo, que consiste em duas fases: um ciclo de reprodução assexuada em humanos e ciclo de reprodução sexuada no mosquito. O plasmódio é inoculado através da picada de mosquitos infectados do sexo feminino. O homem é o único reservatório do parasita da malária humana. A transmissão do plasmódio de uma pessoa doente para uma pessoa sadia ocorre por meio de um vetor, o mosquito Anopheles. A contaminação direta, pessoa a pessoa, só é possível por meio de transfusão de placenta, quando as mulheres grávidas infectadas infectam o filho. O homem não tem imunidade natural contra a malária, mas se ele é submetido a repetidas infestação pode desenvolver uma imunidade relativa, que limita os efeitos patogênicos do parasita. Esta imunidade é estritamente específica para a espécie em questão. Esta é uma imunidade adquirida. Estas pessoas se tornam então portadores assintomáticos da malária (Chauvelot, 2003; Paillat, 2003).

A maioria das doenças mencionadas acima é de particular importância para a comunidade internacional, e se fazem distribuídas pelo território brasileiro de forma heterogênea. A seção seguinte apresenta a situação mais específica do Brasil para as doenças de veiculação hídrica.

\section{Situação das Doenças Relacionadas à Água no Brasil}

Vimos que a relação entre água e saúde está muitas vezes ligada às condições de vida e de desenvolvimento. Para introduzir mais especificamente o caso do Brasil, destacaremos alguns números.

No Brasil, segundo o Censo 2010 do Instituto Brasileiro de Geografia e Estatística (IBGE, 2010) $15,1 \%$ das crianças brasileiras na faixa de zero a 4 anos vivem em áreas em que o esgoto corre a 
céu aberto. A Região Norte é a que se encontra em pior situação: $32,2 \%$ das casas possuem esgoto no entorno. No Nordeste, são $26,3 \%$.

Alguns critérios clássicos existem em saúde pública para a definição de prioridades para intervenção do setor saúde. De modo geral, admitem-se três aspectos principais:

1. Número de indivíduos afetados.

2. Gravidade dos processos mórbidos (medidas pela mortalidade e incapacidade).

3. Existência de tecnologias de prevenção/ controle.

No caso dos agravos relacionados à água, ao aplicarmos estes critérios, podemos definir as seguintes condições, dentre as mais importantes:

\subsection{Diarreia infantil}

Apesar de importante queda nos últimos anos ainda é uma importante causa de morbidade no país. Devendo-se destacar a disparidades geográficas, que reflete nas iniquidades socioeconômicas que ocorrem no país, como pode ser observado na figura 1 que trata a situação das doenças diarreicas agudas em menores de 5 anos. Onde podemos observar altas taxas no norte e nordeste, e alguns bolsões no ressaltante do país.

Na figura 2 mostra a situação da qualidade da água para consumo humano em relação ao parâmetro de coliformes total que está intimamente ligado as doenças diarreicas. Percebe-se que em grande parte do país essa água está comprometida com a presença de coliformes totais e também extensas áreas não realizam as análises necessárias para o monitoramento o que vem a comprometer fortemente a saúde da população que consome essa água.

\subsection{Doenças transmitidas por vetores}

As doenças transmitidas por vetores destacam-se a malária (Figura 3), praticamente restrita a região Amazônica (com cerca de 600 mil casos em 2011) e a dengue (Figura 4), mais importante nas grandes cidades, com cerca de 700 mil casos em 2011.

\subsection{Esquistossomose e outras helmintoses} A esquistossomose origina-se na contaminação fecal (por doentes) de corpos d'água como riachos, lagoas e açudes, que contenham populações do molusco do gênero Biomphalaria. Ela é endêmica na região Nordeste e partes da Sudeste (Figura 5). Estima-se a existência de 8 milhões de portadores no país. Na região

Figura 1: Internações por Doenças Diarreicas Aguda (DDA) em menores de 5 anos em 2011.

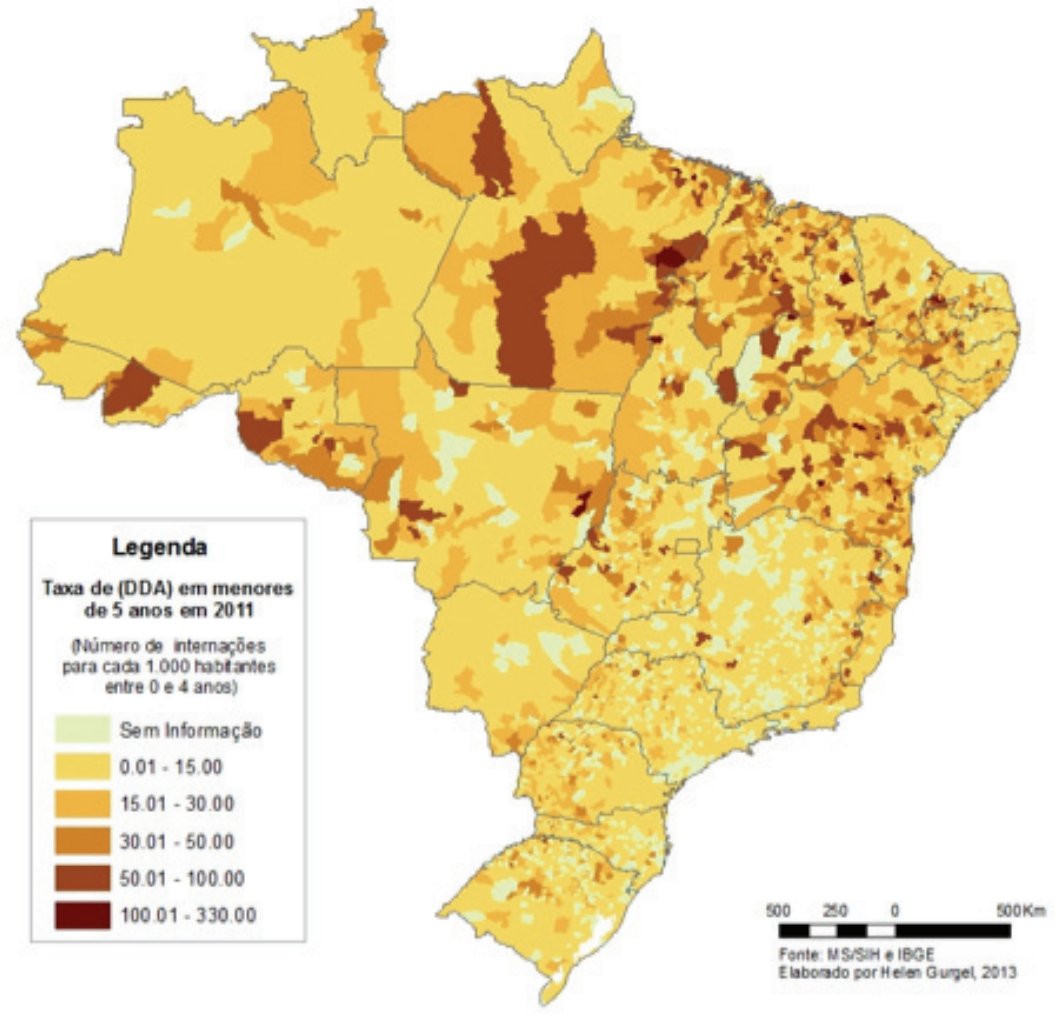


Nordeste, em 2004, foram diagnosticados 43.759 casos novos (incidência de 87,8 casos/100 mil habitantes).

\subsection{Leptospirose}

Leptospirose geralmente ocorre como consequência da contaminação de águas de inundações urbanas pela urina do rato de esgoto, que contém

Figura 2: Porcentagem de amostra do parâmetro de coliformes total das análises de vigilância da qualidade da água em 2011.

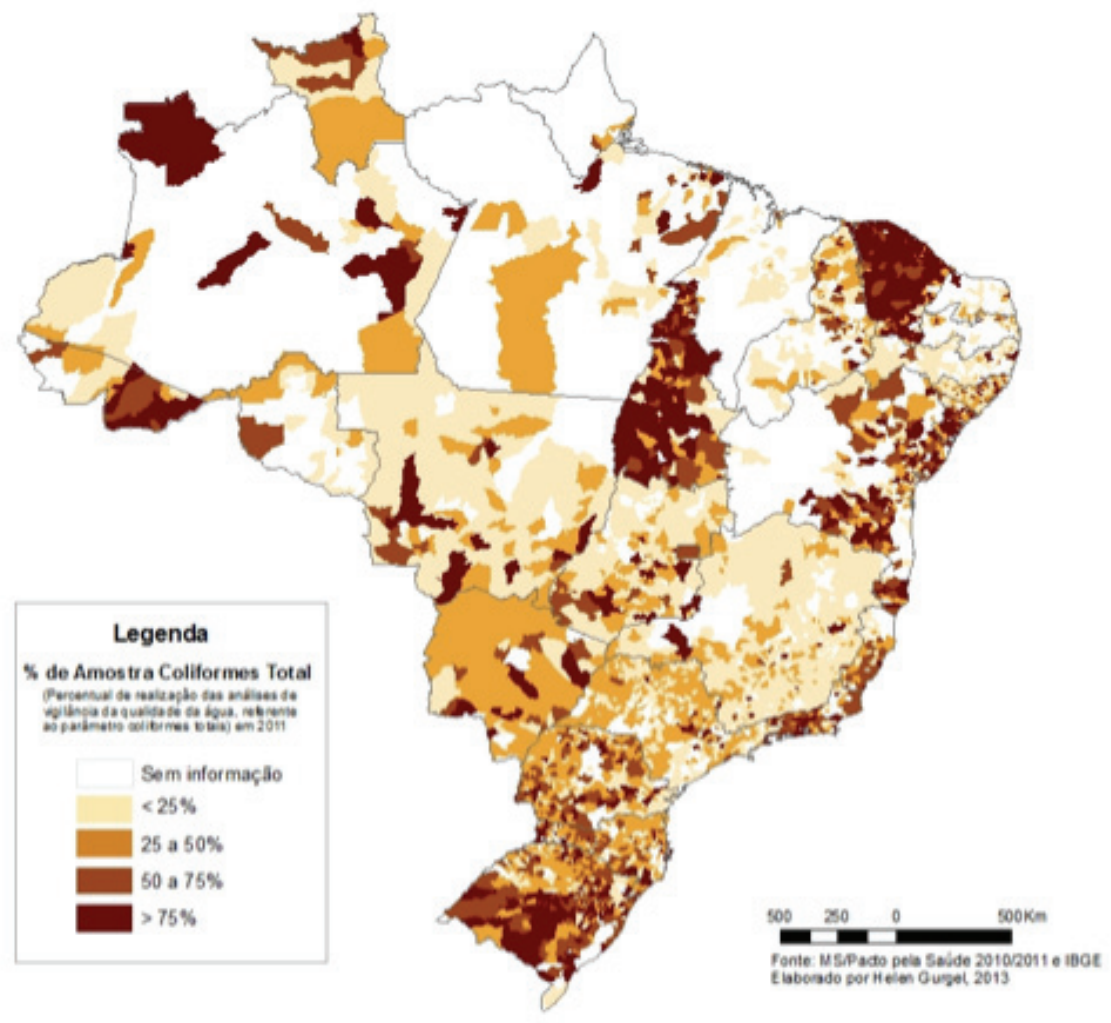

Figura 3: Risco de malaria por municipio de infecção no Brasil, 2011.

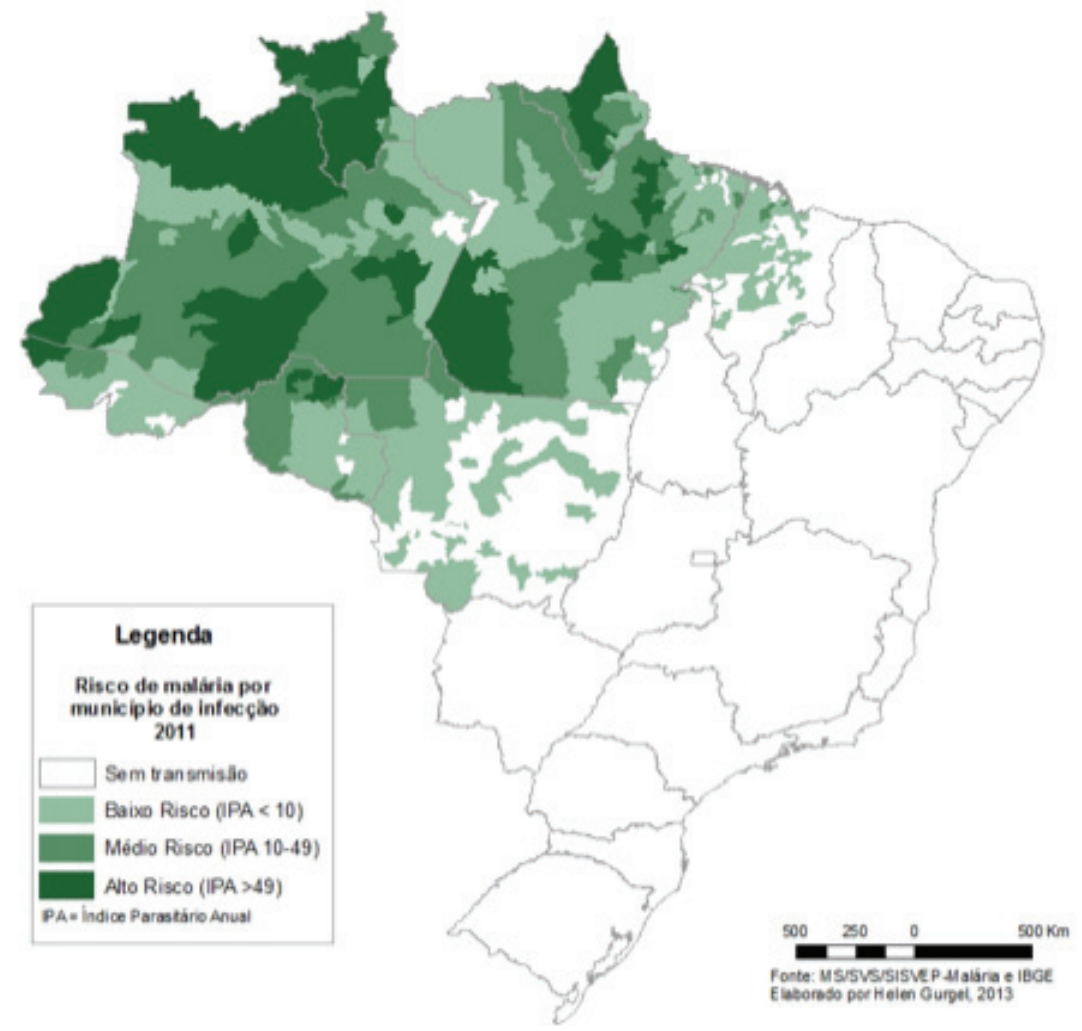


Figura 4: Casos de dengue por município de infecção no Brasil, 2011.

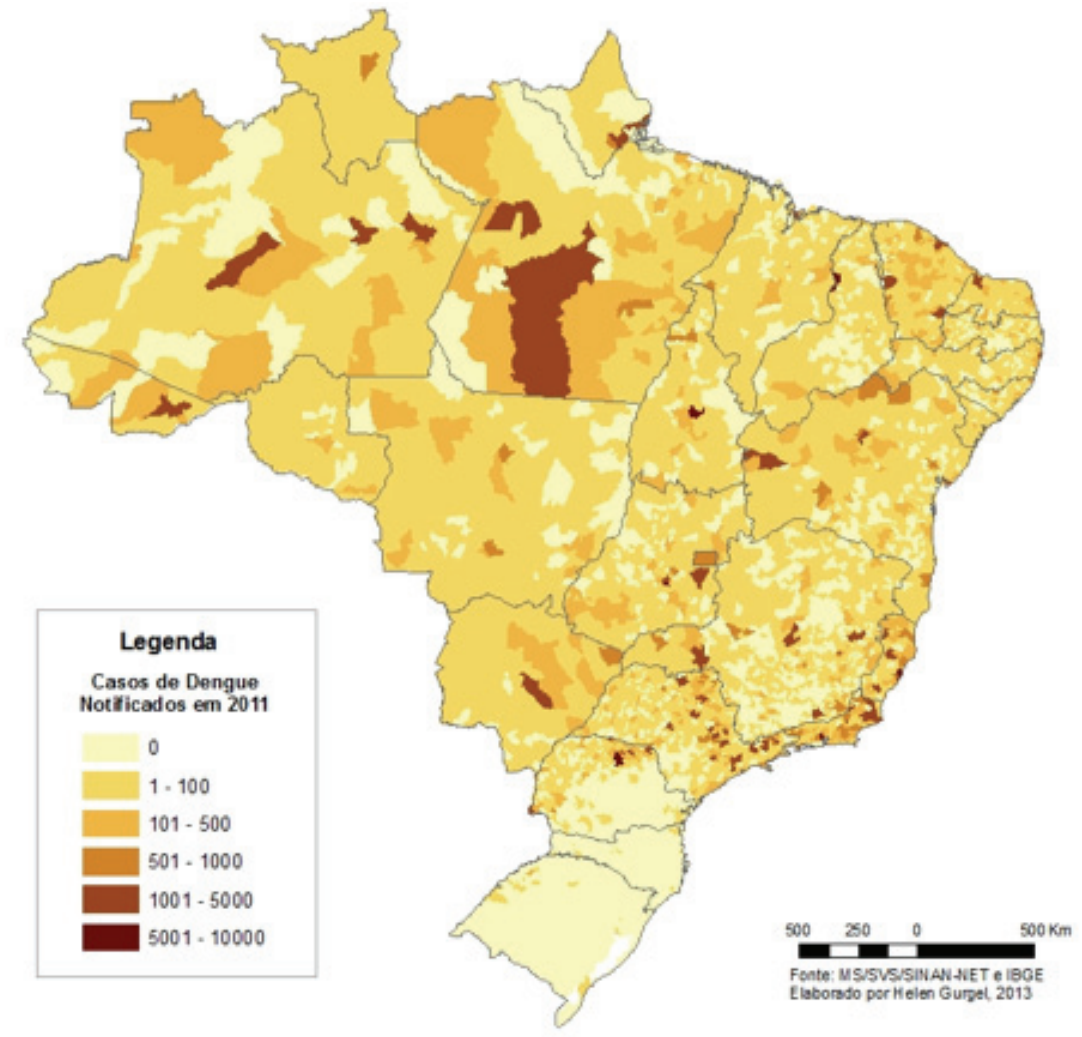

Figura 5: Casos de esquistossomose por municipio de residência no Brasil, 2011.

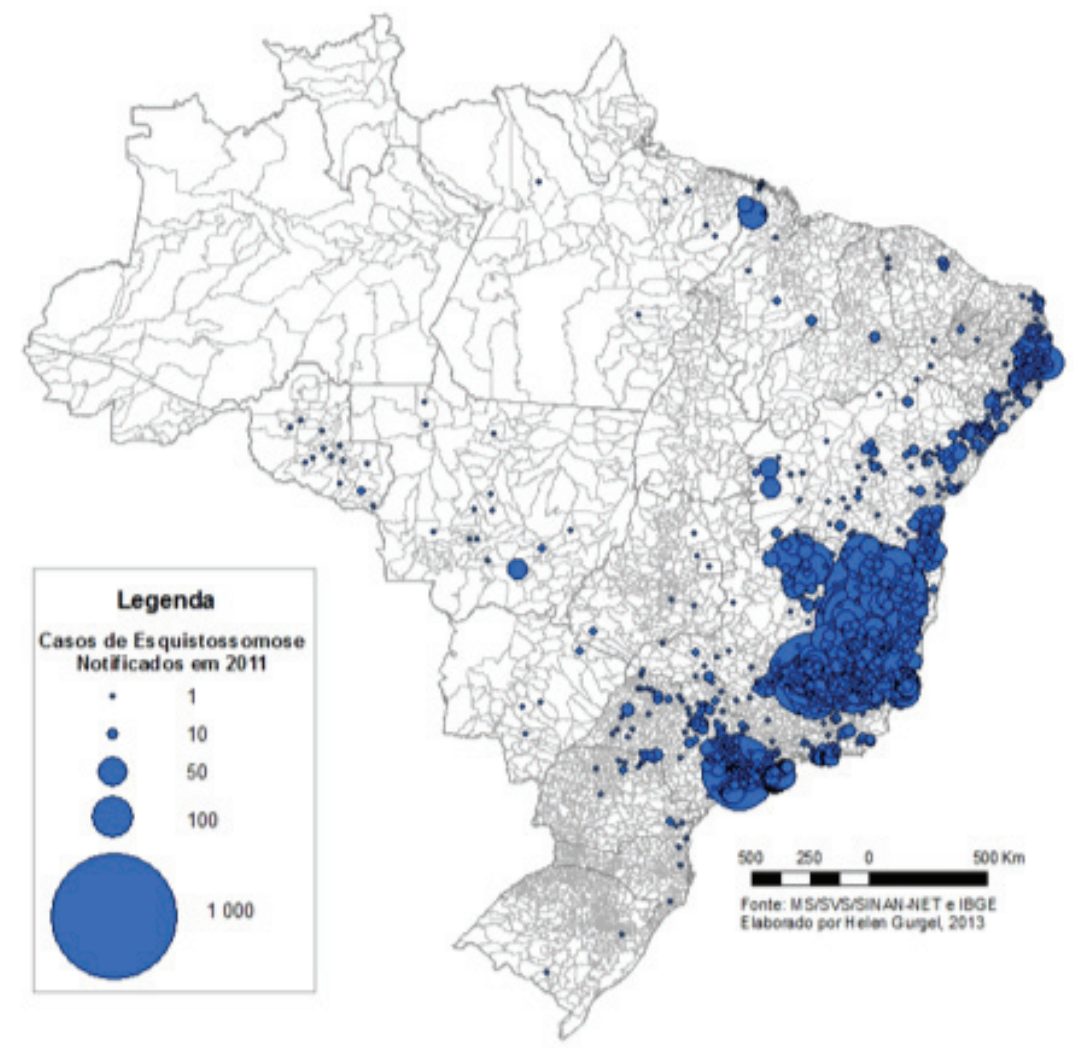

a bactéria causadora (Figura 6). Ela é uma doença de alta letalidade. Entre 1996 e 2005, foram diagnosticados 33.174 casos no país. A maior epidemia já registrada no Brasil foi no verão de 1996, na cidade do Rio de Janeiro, com 1.790 casos e 49 óbitos.

\subsection{Intoxicação por cianotoxinas} Intoxicação por cianotoxinas há diversos relatos entre correlação entre a ocorrência de florações de cianobactérias e agravos a saúde. Em 1988 há evidência de correlação entre a ocorrência de florações de cianobactérias no reservatório de 
Itaparica (Bahia) e a morte de 88 pessoas, entre as 2.000 intoxicadas e que apresentaram um quadro grave de gastrenterite pelo consumo de água do reservatório.

Entretanto, o primeiro caso confirmado mundialmente de mortes humanas causadas por toxinas de cianobactérias ocorreu no início de 1996, quando 130 pacientes renais crônicos passaram a apresentar um quadro clínico uma grave, após terem sido submetidos a sessões de hemodiálise em uma clínica da cidade de Caruaru-PE. As análises confirmaram a presença de cianotoxinas no sistema de purificação de água da clínica e em amostras de sangue e fígado dos pacientes intoxicados.

\subsection{Situações complexas devido à falta crônica de água:}

Os impactos mais importantes são os problemas nutricionais, os quais são exacerbados pela queda na produção de alimentos, e as consequências dos processos migratórios resultantes da economia afetada e que atinge de forma heterogênea o pais (CEDEPLAR/FIOCRUZ, 2008).

\section{4. Água e saúde: Elementos de ação públicas no Brasil}

Embora o Brasil tenha uma posição privilegiada no mundo em relação à disponibilidade de recursos hídricos (12\% da disponibilidade mundial), há disparidades regionais importantes.

Na região Nordeste, por exemplo, existem áreas cuja disponibilidade de água por habitante/ano é menor que o mínimo de 2.000 litros recomendados pela ONU (Marengo, 2008).

Desde 2008, o Brasil, através do Programa de Aceleração do Crescimento (PAC), tem investindo em obras de saneamento básico cerca de 85 bilhões de reais (Trata Brasil, 2012). Apesar desse maciço investimento prevê-se que o Brasil conseguirá atingir a meta do milênio referente ao abastecimento de água, mas terá dificuldades em alcançar a que se refere ao esgotamento sanitário. A melhoria no manejo da água, com sistemas aperfeiçoados, reduz a oportunidade para formação de criadouros de mosquitos transmissores de doenças vetoriais como a dengue e malária que também é uma das metas do milênio.

Figura 6: Casos de Leptospirose por municipio de infecção no Brasil, 2011.

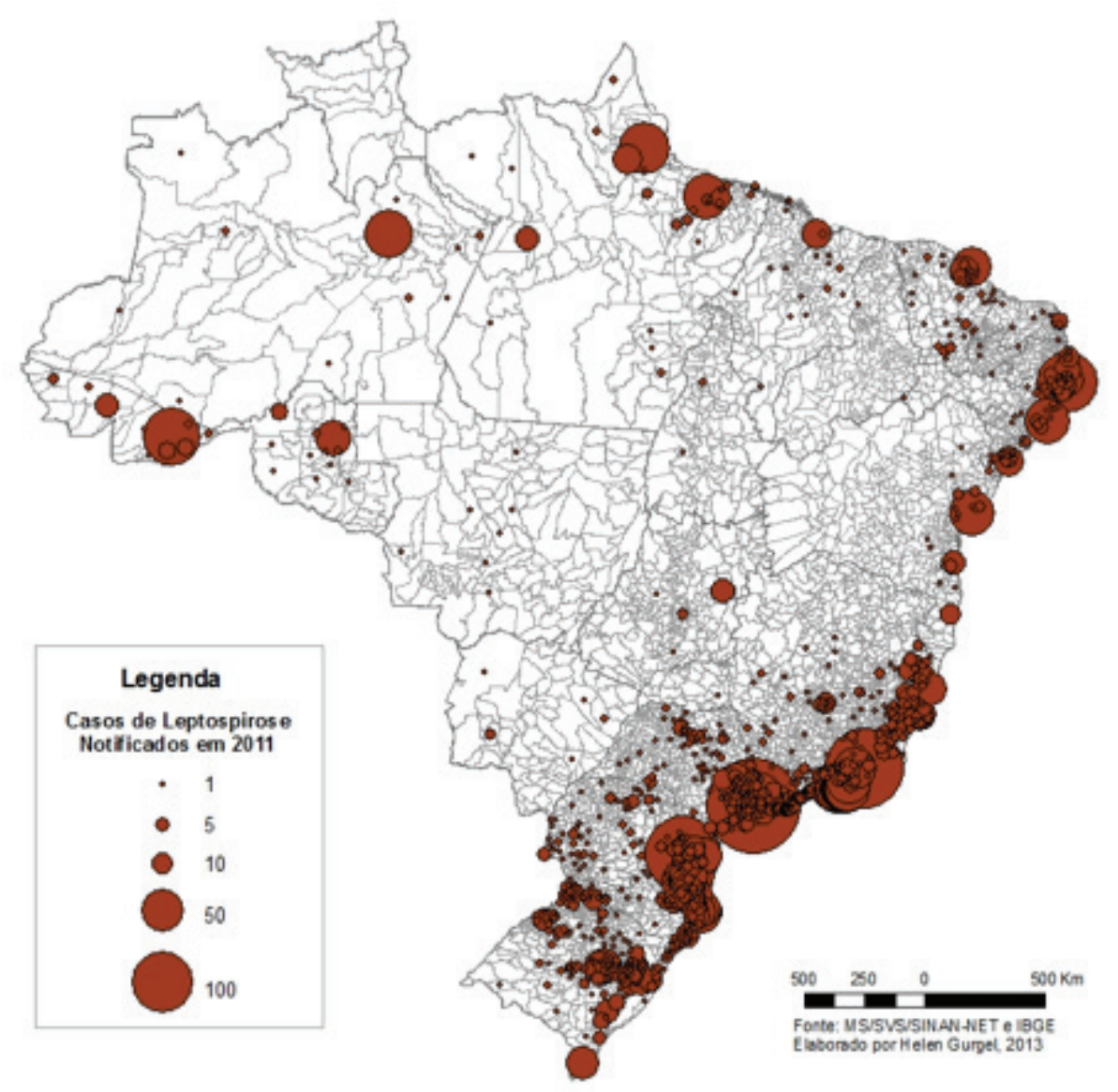




\subsection{Pesquisa, vigilância e monitoramento} Atualmente importantes iniciativas de coleta, organização e disponibilização de dados sobre água, esgotamento sanitário e enfermidades a estes relacionados estão em desenvolvimento.

O Ministério da Saúde desenvolve desde 2000 o sistema de vigilância de qualidade da água para o consumo humano (Vigiagua). Ele consiste no conjunto de ações adotadas continuamente pelas autoridades de saúde pública para garantir à população o acesso à água em quantidade suficiente e qualidade compatível com o padrão de potabilidade, estabelecido na legislação vigente (Portaria MS n. 2914/2011), como parte integrante das ações de prevenção dos agravos transmitidos pela água e de promoção da saúde, previstas no Sistema Único de Saúde - SUS (Freitas e Freitas, 2005). As ações são desenvolvidas pelas Secretarias de Saúde Municipais, Estaduais, e do Distrito Federal e pelo Ministério da Saúde, por meio da Coordenação Geral de Vigilância em Saúde Ambiental. Atualmente, o programa está implementado em todos os estados brasileiros.

O Sisagua foi concebido com base na norma de potabilidade de água, no Programa Nacional de Vigilância da Qualidade da Água para consumo Humano - Vigiagua, na Diretriz Nacional do Plano de Amostragem da Vigilância da Qualidade da Água para Consumo Humano e na definição de indicadores sanitários utilizados na prevenção e no controle de doenças e agravos relacionados ao saneamento. A primeira versão do sistema foi disponibilizada em 2001 e vigorou até 2006. Uma nova versão foi estruturada pela equipe do Vigiagua (Ministério da Saúde) e Datasus, a qual foi disponibilizada em 2007. Diversas melhorias têm sido desenvolvidas, desde então, com o intuito de tornar o sistema cada vez mais completo e permitir um eficaz gerenciamento de riscos à saúde no âmbito do Vigiagua. O sistema pode ser acessado em http://portalweb04.saude.gov. br/sisagua/

Além desta iniciativa o Ministério da Saúde (Coordenação Geral de Vigilância Ambiental) em parceria com a FIOCRUZ desenvolveu e mantem o Atlas da Água, cujo principal objetivo é reunir indicadores de saúde, qualidade da água e saneamento, em nível municipal, em todo o país, o atlas permite a visualização de problemas de abastecimento de água, padrões de consumo e perfil epidemiológico de enfermidades de veiculação hídrica. O Atlas pode ser acessado em http://www.aguabrasil.icict.fiocruz.br/. Também está sendo desenvolvido e mantido pela mesma equipe em conjunto com o INPE (Instituto Nacional de Pesquisas Espaciais) o Observatório de Clima e Saúde que é um projeto que reúne e conjuga informações de diversas naturezas com o objetivo de facilitar a análise da relação entre clima e saúde. A fim de possibilitar alertas e acompanhamento de situações de emergência na saúde geradas por eventos climáticos, além de permitir acompanhar tendências a longo prazo das mudanças ambientais e climáticas. 0 Observatório pode ser acessado em: http://www. climasaude.icict.fiocruz.br/

\section{Conclusão}

A grande maioria dos casos de diarreia e das doenças transmitidas direta ou indiretamente pela água afetam os países em desenvolvimento, e em menor medida, as regiões menos desenvolvidas dos países emergentes. A prevenção ou erradicação desses agravos são complexas, mesmo que sejam apoiados por importantes políticas. De fato, além das suas causas físicas ou ecossistêmicas essas doenças estão inscritas nas práticas sociais (modo de exploração dos recursos naturais aquáticos, mas também terrestres), espaços de vida (proximidade das habitações com os hábitat dos vetores), e se perpetuam com a falta de educação ou de informação das populações afetadas (higiene, alimentação, exposição a vetores, etc.).

Nesse contexto a relação entre água e saúde é bastante estreita e interdepende. O Brasil ainda tem grandes desafios a serem suplantados entre eles implementar políticas públicas que levem em contam as especificidades territoriais deste imenso país. Ter um conhecimento sistêmico dessas relações apoiará a tomada de decisões.

A informação sobre o uso e qualidade da água para o consumo humano se apresenta como fundamental para mapear áreas de vulnerabilidade e apontar tendências, entretanto elas devem considerar as possibilidades de acidentes e eventos extremos, como períodos de estiagem e enchentes, assim como as limitações tecnológicas e operacionais dos sistemas de abastecimento.

As violações das normas de potabilidade devem ser tratadas de forma transparente, entre poder público, empresas e sociedade, de modo que os parâmetros de potabilidade possam ser cumpridos efetivamente e assim a segurar qualidade de vida da população brasileira.

\section{Agradecimentos}

Este trabalho faz parte do projeto CNPq (Brasil) / IRD (França) RELAIS "Sistema de Informacao Regional da Paisagem Epidemiologica na Amazonia" (2012-2016) - Programa de Cooperação 
e Apoio a Redes de Pesquisa Brasileiras e Francesas.

\section{Referências}

ARNELL, N.W. Climate change and global water resources: SRES emission scenarios and socioeconomic scenarios. 2004. Global Environ Change, v.14, p. 31-52.

CAPRON, M. Stratégies vaccinales contre les grands fléaux des pays en développement. 2004. L'exemple de la bilharziose. Les Nouvelles pharmaceutiques, $n^{\circ} 385$.

CEDEPLAR/UFMG e FIOCRUZ. Mudanças climáticas, migrações e saúde: cenários para o nordeste brasileiro, 2000-2050. 2008. Disponível em: http://www.cedeplar.ufmg.br/pesquisas/migracoes_saude/MIGRACAO_E_

SAUDE_NORDESTE.pdf

CHAUVELOT, F. Le paludisme, Le Moniteur des pharmacies, $n^{\circ} 91.2003$.

CHAUVELOT, F. L'amibiase, Le Moniteur des pharmacies, $n^{\circ} 145.2006$.

CONFALONIERI, U.E.C.; HELLER, L. \& AZEVEDO, S. Água e Saúde: aspectos globais e nacionais. In: Bicudo, C. (Org.). Água no Brasil: análises estratégicas. São Paulo: Instituto de Botânica, 2010, p. 27-38.

FREITAS, M.B. \& FREITAS, C.M. A Vigilância da qualidade da água para consumo humano: desafios e perspectivas para o Sistema Único de Saúde. Ciência \& Saúde Coletiva, 2005, v.10, n.4, p.993-1004.

GONDIM, G.M.D.M., MONKEN, M., ROJAS, L.I., BARCELLOS, C., PEITER, P., NAVARRO, M.B.M.A. \& GRACIE, R. O território da saúde: a organização do sistema de saúde e a territorialização. In: Miranda A.C., Barcellos C., Moreira J. \& Monken M. (Org.) Território, Ambiente e Saúde. Rio de Janeiro: Fiocruz, 2008, p. 237-255.

IBGE. Instituto Brasileiro de Geografia e Estatística. Censo Demográfico 2010: Resultados do Universo. Disponível em: ftp:// ftp.ibge.gov.br/Censos/Censo

Demografico_2010/Resultados_do_Universo

MARENGO, J.A. Água e mudanças climáticas. Estudos Avançados, 2008. v.22, p.83-96.

MONKEN, M. \& BARCELLOS, C. Vigilância em saúde e território utilizado: possibilidades teóricas e metodológicas. Cadernos de Saúde Pública, 2005, v. 21, n. 3, p.898-906.

PAILLAT, B. Le paludisme, Le Moniteur des Pharmacies, 2003, $n^{\circ} 91$.

PICOT, S. L'amibiase, Le Moniteur des Pharmacies, 2006, $n^{\circ} 145$.

PRÜSS-USTIN, A.; BOS, R.; GORA, F. \& BARTRAM, J. Safer Water, better health. Costs, benefi ts and sustainability of interventions to protect and promote health. WHO, Geneva, 2008, 53 p. Disponível em: http://www. who.int/quantifying_ehimpacts/publications/saferwater/en/index.html

TRATA BRASIL. 3 anos de acompanhamento do PAC. 2012. Disponível em: http://www.tratabrasil.org.br/datafiles/uploads/deolhonopac/book-final.pdf

UNITED NATIONS STATISTICS DIVISION. Millennium Development Goals Indicators. 2008. Disponível em http://mdgs.un.org/unsd/ $\mathrm{mdg} /$ default.aspx 